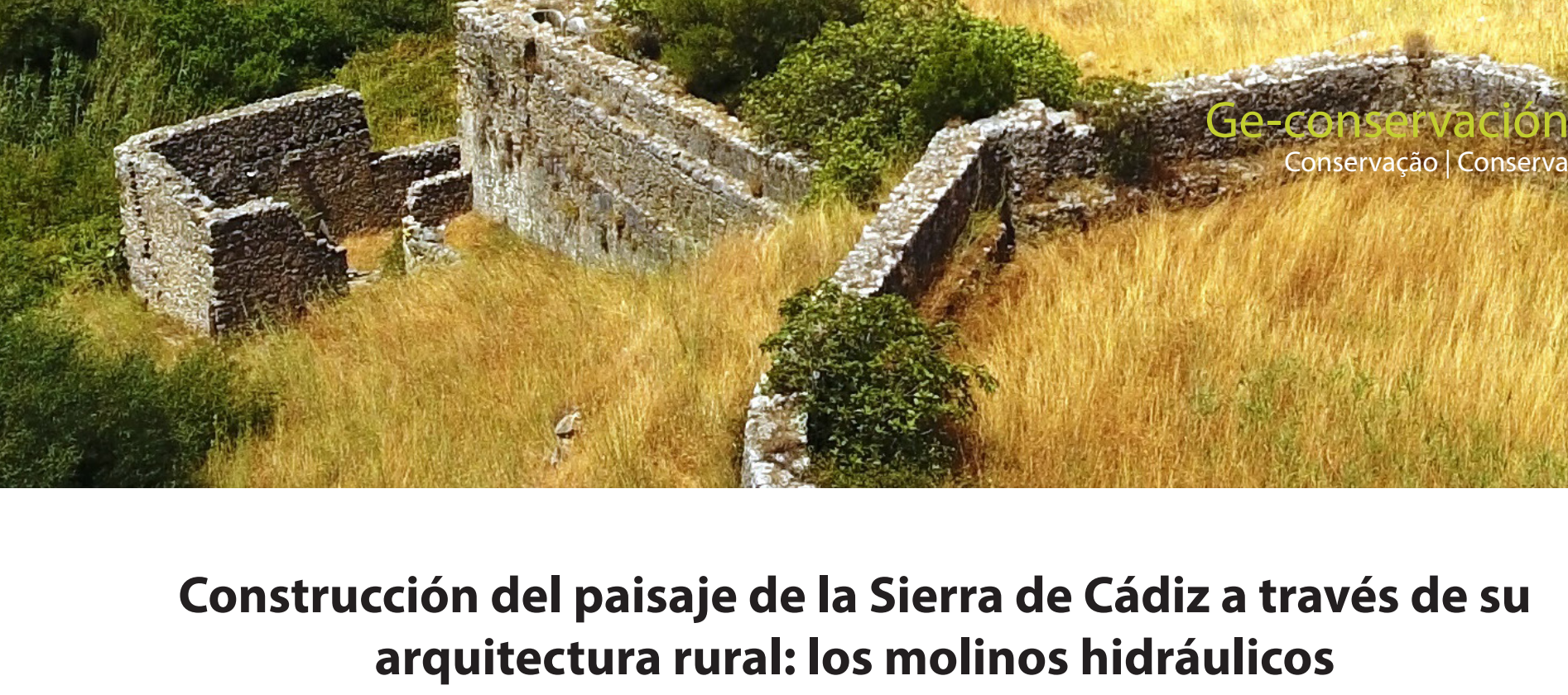

\title{
Construcción del paisaje de la Sierra de Cádiz a través de su arquitectura rural: los molinos hidráulicos
}

\author{
Gloria Rivero-Lamela
}

Segunda selecionada en la convocatoria Joven Investigador GEIIC 2018

\begin{abstract}
Resumen: Este artículo analiza una arquitectura rural e industrial en un entorno concreto: los molinos hidráulicos harineros en la Sierra de Cádiz. Estas construcciones productivas y anónimas, repartidas estratégicamente por el territorio, son partes constitutivas de la cultura rural y construyen el paisaje serrano, porque han colaborado en la antropización y vertebración del territorio. Son también pequeñas infraestructuras hidráulicas que responden a las condiciones hidrográficas y orográficas de la comarca, en una relación de simbiosis entre recursos naturales y sociedad. A pesar de sus valores inherentes, los molinos han quedado al margen de la valoración, catalogación y protección oficial. La metodología de investigación aplicada (con base en la Taxonomía de Bloom y de acuerdo a la Guía Europea de observación del patrimonio rural-CEMAT) pone en valor estas arquitecturas y ha permitido deducir la importancia de estas construcciones en la lectura histórica y logística del territorio así como su legado patrimonial, arquitectónico, artesanal y cultural.
\end{abstract}

Palabras clave: construcción del paisaje, territorio, paisaje, arquitectura rural, molino hidráulico, Sierra de Cádiz, patrimonio cultural

\section{Construction of the landscape of the Sierra de Cádiz through its rural architecture: the water mills}

\begin{abstract}
This paper ${ }^{1}$ analyses a rural and industrial architecture in a specific environment: the water flour mills in the Sierra de Cádiz. These productive and anonymous constructions, strategically distributed throughout the territory, are constitutive parts of the rural culture and construct the mountain landscape, because they have collaborated in the anthropization and structuring of the territory. These mills are also small hydraulic infrastructures that respond to the hydrographic and orographic conditions of the region, in a relationship of symbiosis between natural resources and society. Despite their inherent values, they have been left out of the valuation, cataloguing and official protection. Applied research methodology (based on Bloom's taxonomy and according to European Rural Heritage Observation Guide-CEMAT) gives value to these architectures and can enable us to deduce the importance of these constructions in the historical and logistic reading of the territory as well as its patrimonial, architectonic, artisan and cultural legacy.
\end{abstract}

Keyword: landscape construction, territory, landscape, rural architecture, water mill, Sierra de Cádiz, cultural heritage

\section{Construção da paisagem da Serra de Cádiz através da sua arquitetura rural: moinhos hidráulicos}

Resumo: Este artigo' analisa uma arquitetura rural e industrial num contexto específico: os moinhos de farinha hidráulicos na Serra de Cádis. Estas construções produtivas e anónimas, repartidas estrategicamente por todo o território, são partes constituintes da cultura rural e constroem a paisagem de montanha, porque colaboraram na antropização e estruturação do território. São também pequenas infraestruturas hidráulicas que respondem às condições hidrográficas e orográficas da região, numa relação de simbiose entre os recursos naturais e a sociedade. Apesar dos seus valores intrínsecos, os moinhos ficaram à margem da avaliação, catalogação e proteção oficial. A metodologia da investigação aplicada (baseado na Taxonomia de Bloom e de acordo com o Guia Europeu para a Observação do Patrimônio Rural - CEMAT) agrega valor a essas arquiteturas e permitiu deduzir a importância destas construções na leitura histórica e logística do território e do seu legado patrimonial, arquitetónico, artesanal e cultural.

Palavras-chave: construção da paisagem, território, paisagem, arquitetura rural, moinho hidráulico, Serra de Cádiz, património cultural 


\section{Introducción}

Los molinos hidráulicos harineros de la Sierra de Cádiz² son arquitecturas rurales, productivas y anónimas que se reparten estratégicamente por el territorio. A su vez, son partes constitutivas de la cultura rural y construyen el paisaje serrano, porque han colaborado en la antropización y vertebración del territorio, en una relación de simbiosis entre territorio, recursos y sociedad que hasta hace poco ha caracterizado culturalmente esta Sierra. Conforman un sistema complejo compuesto, además de por los edificios, por los mecanismo y pequeñas obras de infraestructura hidráulica que posibilitaban su funcionamiento, "each one defined by the modification and stratification processes that occurred over the centuries, standing as testimonials to past cultures and events"3 (Centofanti et al. 2016: 95).

La existencia y supervivencia de sus más de 80 molinos hidráulicos revelan la importancia histórica de la molienda en la región, y explican la funcionalidad pasada del territorio, evidenciando la trascendencia y rendimiento de la red hidrográfica comarcal.

A pesar de sus valores inherentes, estas arquitecturas han quedado al margen de la valoración, catalogación y protección oficial, y solo los que se sitúan dentro de los límites del Parque Natural Sierra de Grazalema (37 de los 85 molinos harineros) cuentan con el resguardo de esta protección ambiental. Aunque la mayoría se encuentra en ruinas por los cambios funcionales o "mutaciones profundas" (Oliva Serrano 1997: 322) acontecidas en el medio rural y la obsolescencia de la molienda artesanal, siguen constituyendo una red de patrimonio (pre) industrial, hoy en peligro, que aporta una interesante lectura histórica y logística del territorio [figura 1].

Es preciso conocer, valorary conservar estas construcciones porque atestiguan una serie de valores de carácter no solo arquitectónico, sino también paisajístico, social, artesanal y etnográfico al ser huellas de nuestro pasado reciente y vestigios de la memoria colectiva; valores que "permanecerán en tanto lo hagan los molinos y aquellas infraestructuras que los conectaban" (Ramos-Carranza y Rivero-Lamela 2018: 98).

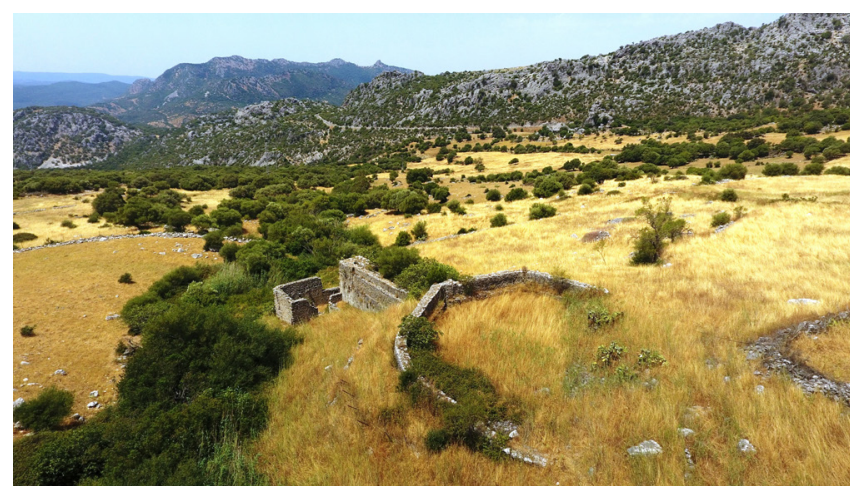

Figura 1.- Molino harinero "Segundo". Ribera del Arroyo Seco, en Benaocaz. Fuente: fotografía con dron de la autora

\section{Objetivos}

Es objetivo general de este Trabajo analizar, estudiar e investigar sobre arquitecturas rurales productivas molinos hidráulicos- que forman parte de una entidad territorial con valores patrimoniales -Sierra de Cádiz-, integrando así arquitectura y paisaje. Se trata de realizar una nueva lectura patrimonial del territorio, utilizando los molinos como piezas a través de las cuales reflexionar sobre la construcción de su paisaje y entender y mirar la realidad global de la sierra gaditana. Como objetivos específicos se pueden enunciar los siguientes:

- Ofrecer una metodología, una base sistemática de estudio de la arquitectura rural productiva con posibilidad de ser aplicada a diferentes realidades geográficas.

- Puesta en valor de estas arquitecturas rurales menores. Extraer sus valores patrimoniales.

- Revisión de la normativa, planes, guías y cartas que repercuten en la arquitectura rural y el paisaje desde un punto de vista urbanístico, de ordenación del territorio, medioambiental y patrimonial. Presentar el marco político y normativo en el que estos bienes se encuadran.

- Estudio de la cartografía histórica de la Sierra de Cádiz. Elaboración de nuevos estratos cartográficos y nuevas planimetrías que intenten abarcar lo material y físico, la historia, la evolución y lo conceptual.

\section{Justificación y planteamiento}

La arquitectura rural productiva, conformada por molinos, pósitos, cillas, tercias, cortijos, haciendas, lagares, etc., constituye uno de los conjuntos constructivos más significativos de la edificación civil del sur de la península ibérica. Acorde a esta importancia, "el paso del tiempo ha perfilado un horizonte constructivo de una riqueza y diversidad poco frecuentes, cuyos valores y mera supervivencia, sin embargo, se han visto gravemente amenazados en las últimas décadas a raíz de las transformaciones que han afectado al medio rural" (Olmedo Granados 2002: 15). Estas arquitecturas explican el territorio en el que se sitúan, e incluso en su estado actual de desuso y letargo, justifican la estructura social, cultural y económica de una región.

Partir de estos elementos para reflexionar y observar el territorio puede dar lugar a interesantes lecturas patrimoniales del mismo y construcciones de sus paisajes. Se elige como ámbito de estudio la comarca de la Sierra de Cádiz. Situada en el extremo nororiental de la provincia, esta región cuenta con unos aspectos fisiográficos, paisajísticos y humanos diferenciadores. Limita con Sevilla al norte y con Málaga al este. Al sur, la sierra Aljibe constituye una clara diferencia desde el punto de vista litológico. El límite occidental supone 
el contacto entre campiña y sierra, que se produce de forma brusca debido a los relieves que se extienden de norte a sur desde la sierra de Nava hasta las estribaciones de la sierra de Ubrique. Esta delimitación se ajusta a la que propone la actual Comarcalización Agraria (2012) del Ministerio de Agricultura, Pesca y Alimentación. Sin embargo, no coincide con la Unidad Territorial (UT) que establece el Plan de Ordenación del Territorio de Andalucía (POTA), que unifica las Serranías de Cádiz y Ronda (enmarcándolas en una UT organizada por Redes de Ciudades Medias Interiores), al igual que la Demarcación de Paisaje Cultural que establece el Instituto Andaluz del Patrimonio Histórico (IAPH).

Las condiciones hidrográficas, orográficas y culturales de la comarca (el carácter "serrano" al que alude Escalera Reyes, 1980: 274) han definido una forma de ocupación territorial determinada por la dispersión y estructuración en pequeñas propiedades, y un sistema socioeconómico sustentado por las actividades agrícolas, ganaderas $y$, con gran significación, una industria artesana basada en el aprovechamiento de los ríos: la molienda. Todos estos aspectos, unidos a los procesos históricos de aislamiento de la comarca, han propiciado la supervivencia de una de las arquitecturas rurales productivas por antonomasia: los molinos hidráulicos. Este Trabajo ha contabilizado, localizado e inventariado un total de 85 molinos a través de compaginar el estudio y análisis de fuentes históricas (tanto documentales como cartográficas) con el trabajo de campo [figura 2].

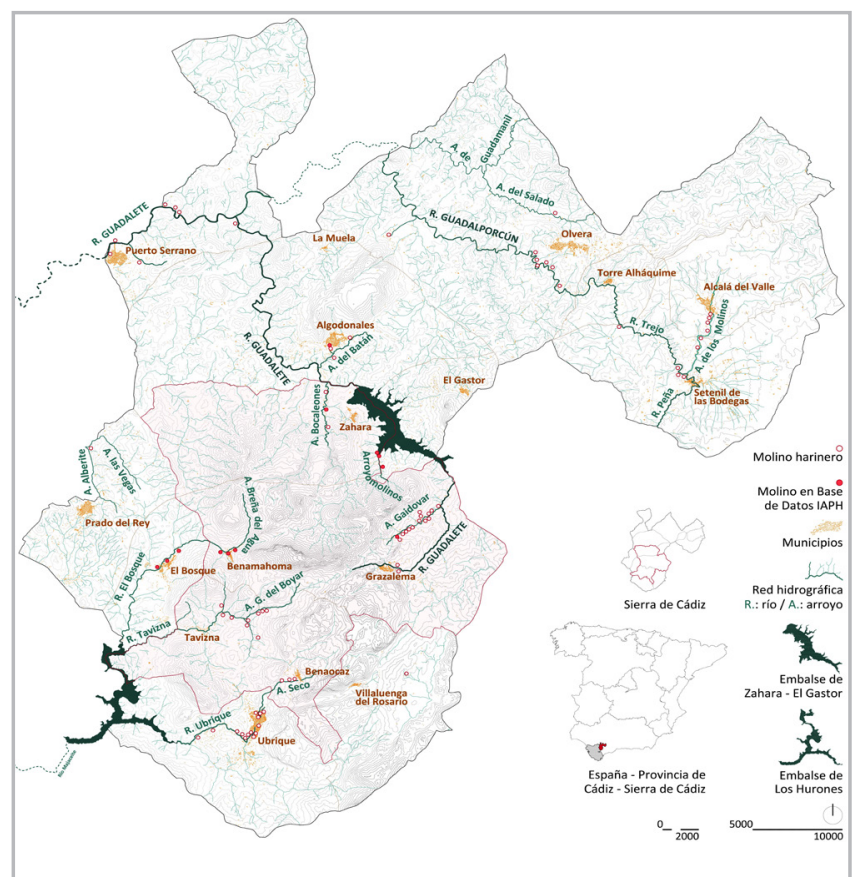

Figura 2.- Plano del medio físico y territorial de la Sierra de Cádiz: topografía, hidrografía y municipios. Localización de los 85 molinos hidráulicos. Área delimitada: 37 molinos estudiados individualmente. Fuente: elaboración propia a partir de la Base Cartográfica de Andalucía básica de 2013, Instituto de Estadística y Cartografía de Andalucía (IECA)
Origen de vida y cultura, los molinos han sido generadores de infraestructuras de comunicación -caminos, cañadas, veredas y sendas- y pequeñas obras hidráulicas canales, acequias y estanques-, y han convivido de forma asociativa con los núcleos de población cercanos, con otras construcciones rurales y con las tierras de cultivo.

Además de ser objetos de análisis en símismos, los molinos suponen un medio para mostrar la entidad geográfica y los paisajes de la comarca objeto de estudio, la Sierra de Cádiz. Estos valores esenciales, junto a la singularidad que estas arquitecturas poseen, su constante proceso de deterioro, tanto por la escasa protección a la que están sometidos como por la falta de uso en que se encuentran muchos de ellos y la inexistencia de inventariado y catalogación ${ }^{4}$ han impulsado y motivado la elección de este tema como punto de partida de esta investigación. Asimismo, la bibliografía sobre este tema en el ámbito concreto de estudio es muy escasa (destacan las valiosas aportaciones de Javier Escalera Reyes en los años 80), por lo que se precisan estudios que aborden estas cuestiones y desvelen estas arquitecturas olvidadas.

Dado el sentido productivo y su condición de hábitat, estas arquitecturas rurales denotan una estrecha dependencia del contexto geográfico, convirtiéndose en testimonios palpables de cultivos, sistemas de explotación, estructuras de propiedad y otros factores decisivos en el modelado y evolución de un territorio concebido como un artificio; una construcción cultural que compendia todas las transformaciones del medio para adaptarlo a las necesidades de las sociedades que lo habitan [figura 3].

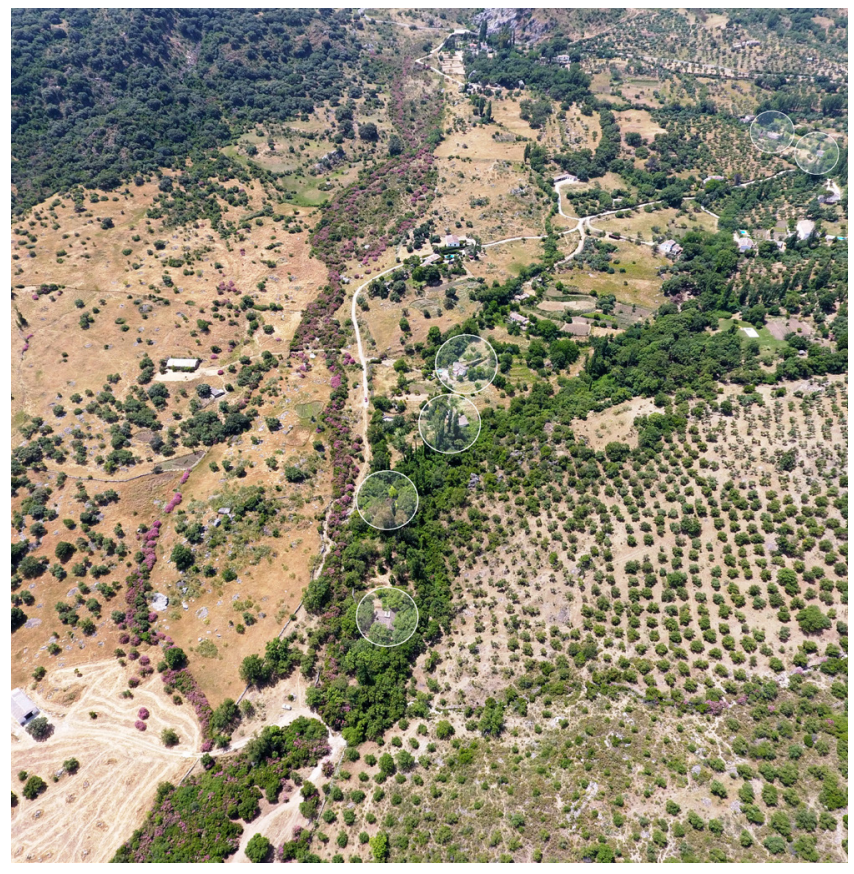

Figura 3.- P.- Tramo de la ribera del Gaidóvar, en Grazalema. Presencia de 6 molinos (dcha. a izq.): Molino "de la Cruz", "El Rincón" “El Pero", “El Portal”, “El Algarrobo" y "La Pasá de Zahara”. Fuente: fotografía con dron de la autora 
Como afirma J. B. Jackson (1984: 8), "a landscape is not a natural feature of the environment but a synthetic space, a man-made system of spaces superimposed on the face of the land, functioning and evolving not according to natural laws but to serve a community (...). It is one thing that all generations and all points of view have agreed upon"5.

Se plantea en este trabajo plasmar estas alteraciones -o acuerdos en la construcción del paisaje- mediante nuevas cartografías territoriales. Un punto de vista muy interesante sobre la importancia de la arquitectura -la tecnología- en la dinámica morfológica del territorio la proporciona Vittorio Gregotti (1972: 84), quien sostiene que "los elementos de transformación histórica de la figura del paisaje van desde la variación climática y estacional a los sistemas de colonización, abarcando la culturización de los fenómenos de retorno del elemento natural (...) pero de modo más amplio, a las figuras que, más allá de toda intención, la explotación productiva crea a partir de la modificadora intervención tecnológica".

La construcción del territorio y por ende, del paisaje, se verifica en una escala espacial y temporal que supera la dimensión local; por eso este estudio debe realizarse desde todas las escalas posibles, en las que el objeto -los molinos hidráulicos- y el territorio -Sierra de Cádiz- fijan los límites físicos, mínimo y máximo del estudio, que no constituyen, sin embargo, dos niveles de reflexión estancos y opuestos: una visión holística de la arquitectura rural productiva que, a pesar de su carácter disperso, da lugar a interesantes redes, proporcionando nuevas lecturas del territorio, ofreciéndonos las claves para entender su estado actual. Desde el extremo de la edificación, su análisis resulta esencial a la hora de comprender su arquitectura como una parte más del territorio, piezas que, cuando son miradas, construyen el paisaje que se pretende mostrar.

\section{Metodología}

Con base en la taxonomía de Bloom (conocimientocomprensión-aplicación-análisis-síntesis-evaluación) y de acuerdo a las directrices europeas de observación del patrimonio rural ${ }^{6}$, se plantean unos descriptores generales y procedimientos (en muchos casos solapados en el tiempo) que generan los textos, dibujos y cartografías encaminados a alcanzar los objetivos propuestos:

CONOCIMIENTO Y COMPRENSIÓN. Revisión de antecedentes, estado de la cuestión y localización de los molinos hidráulicos

-1. Precisar el proyecto: construcción del paisaje de un territorio a través de su arquitectura rural, los molinos hidráulicos.

-2. Adquisición y profundización: En el conocimiento del territorio, del paisaje y de la geografía cultural, así como de la arquitectura rural.

-3. Análisis: Del marco administrativo y normativo que encuadra el tema de estudio.

\section{-4. Elegir un área e identificar el patrimonio rural:}

la Sierra de Cádiz y sus molinos harineros, ya que es susceptible de un enfoque global por constituir una unidad biogeográfica y una "región cultural" (Suárez Japón 1982). Conocimiento objetivo del área.

Esta es la etapa orientada a establecer el marco teórico y a contabilizar los antiguos molinos hidráulicos de la Sierra. Con ese fin, las fuentes de información más importantes para aproximarnos a la distribución de los molinos hidráulicos son, ordenadas cronológicamente, los siguientes:

- F1: Catastro de Ensenada (1750-1754): de las 40 preguntas de esta encuesta interesa la número 17. En sus respuestas se encuentra información sobre el número de molinos existentes en cada pueblo, y para cada uno de ellos, el número de empiedros que poseía, la identidad de su propietario, la renta que procuraba a él y al molinero, el número de meses al año en los que se encontraba en funcionamiento, su tipología constructiva, etc. [figura 4].

- F2: Diccionario de Madoz (1846-1850): el dato que nos atañe se recoge en la información acerca de la Industria de cada término, donde se indica el número de molinos harineros y otras fábricas, aunque en muchas ocasiones no se precisa la cantidad, aludiendo a varios o porción de molinos harineros [figura 5].

- F3: Minutas planimétricas (1873-1874): son mapas manuscritos en papel, elaborados como trabajo previo a la realización del primer Mapa Topográfico Nacional (MTN). Las minutas se dibujan por cada municipio y constituyen la base gráfica existente más antigua, técnica y homogénea para todo el territorio español, coincidente con la plena actividad de las pequeñas industrias rurales (como molinos, ranchos, batanes...). Además de situar las arquitecturas dispersas, muestran aspectos del medio físico oportunos para la lectura e interpretación del paisaje que se acomete: accidentes geográficos, red hidrográfica, red viaria, cultivos (especificando clase, tipo y ocupación). La información toponímica que recogen, tanto de las arquitecturas rurales como de los ríos y vías de comunicación, la precisión en la ubicación de las construcciones, su registro y el de caminos hoy desaparecidos, convierte a las minutas 
en documentos patrimoniales de gran valor [figura 6]. En esta investigación constituyen la fuente de información histórica más fiable para el recuento y ubicación de los molinos harineros. Esto ha motivado la recomposición del mapa comarcal de la Sierra de Cádiz -inédito- de 1874, para el análisis regional de la red de infraestructuras territoriales y arquitectónicas que posibilitaba la producción de harina en el siglo XIX (mapa conceptual con base en las Minutas [figura 7]); también se estudia cómo ha llegado esa urdimbre de caminos, ríos, canales y molinos a la actualidad.

\section{- F4: Aportaciones de Javier Escalera Reyes (1980- 1984).}

\section{- F5: Base de Datos del Patrimonio Inmueble de Andalucía} del IAPH.

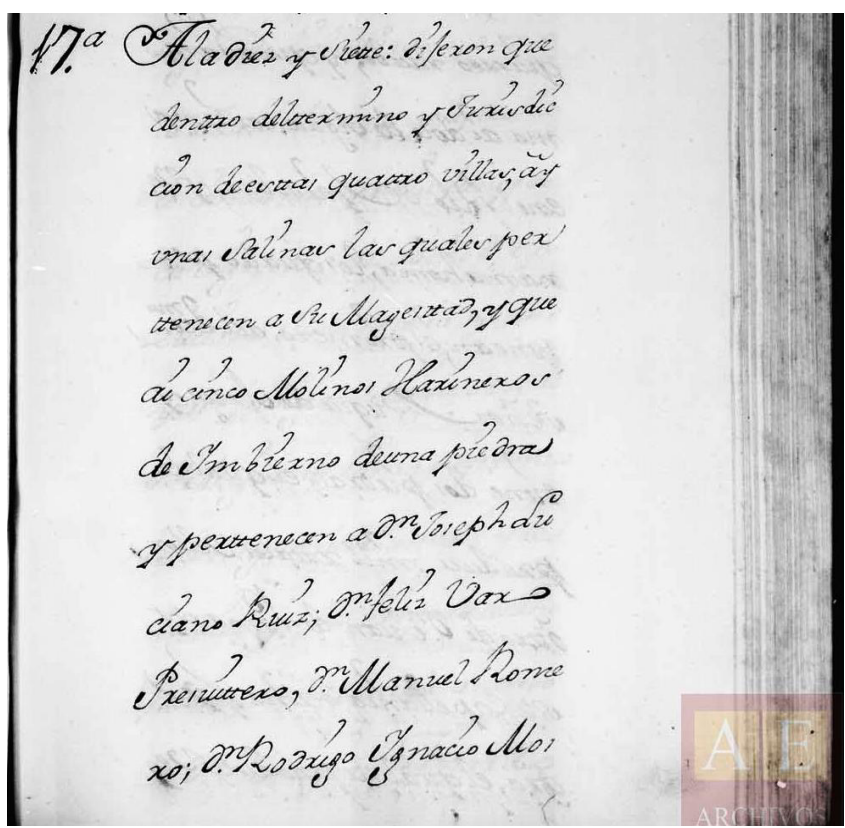

Figura 4.- Grazalema. Respuesta a la pregunta $n^{\circ} 17$ del Catastro de Ensenada. Código de la imagen: AGS_CE_RG_ L288_540. Fuente: Portal de Archivos Españoles (PARES). Parte de la transcripción: "... dijeron que dentro del término (...) ai cinco Molinos Harineros de Imbierno de una piedra y pertenecen a...; y que ai doce de Agua continua en el Rio de Gaidobar, y Benamahoma, los quales pertenecen, el primero del Imo. Señor Duque de Arcos y tiene dos piedras, el qual le produce..."

\begin{abstract}
mata baja. Los Gaminos locales y malos. El correo se recibe de Ronda, tres veces en la semana. prod. toda clase de cereales bastantes para el consumo, algunas legumbres y mucbas frutas; hay ganado de toda especie, y caza de de conejos y perdices. IND.: la agrícola y varios molinos harineros y de aceite. PoBL.: 374 vec., 1,151 almas RiQUEzA PROD.: 4.000,880 rs. IMP.: 50,280 . El PEESUPUEsTo MUNICIPAL asciende á 40,000 rs., y se cubren con el prod. de los bienes de propios.
\end{abstract}

Figura 5.- Zahara. Diccionario de Madoz. Tomo XVI, p. 448. Fuente: Biblioteca Virtual de Andalucía. Consejería de Cultura. Junta de Andalucía. Parte de la transcripción: "IND.: la agrícola y varios molinos harineros y de aceite"

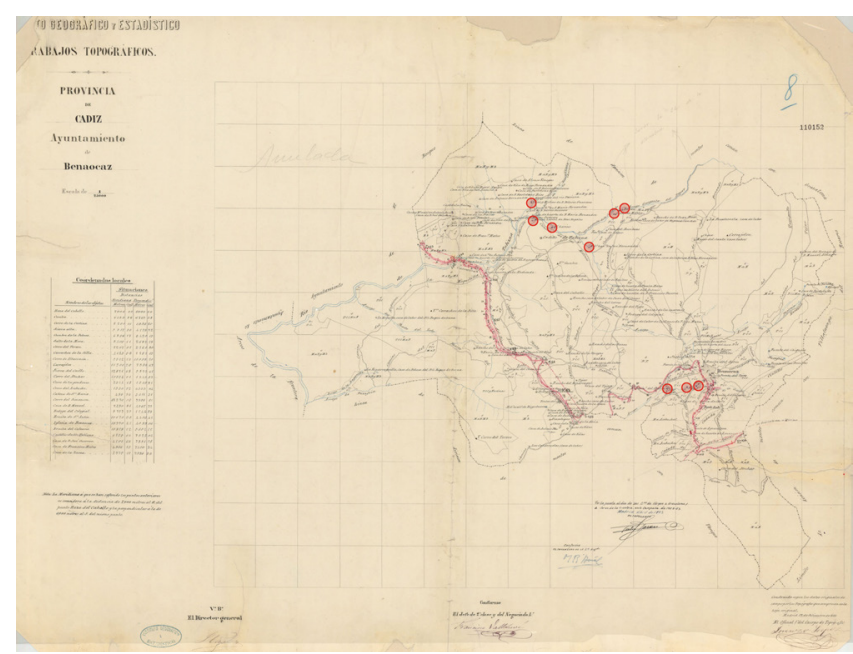

Figura 6.- Minuta Planimétrica del término municipal de Benaocaz. 1873. Localización de 10 molinos hidráulicos. Fuente: Instituto Geográfico Nacional (IGN)

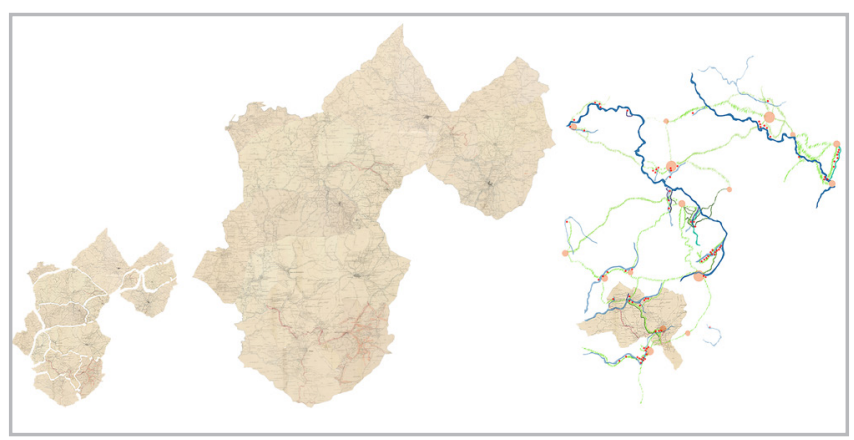

Figura 7.- Mapa de la comarca de la Sierra de Cádiz conformado por las Minutas Planimétricas de sus 14 municipios, 1873-74. Dcha.: Mapa conceptual de las infraestructuras históricas de la producción de harina de la Sierra de Cádiz Fuente: elaboración propia a partir de las Minutas de cada municipio procedentes del IGN

Cada una de las fuentes utilizadas contabiliza un número distinto de molinos [tabla 1], por lo que se precisa actualizar esta información con el necesario trabajo de campo que permita "confrontar la teoría con la práctica en la búsqueda de la verdad objetiva" (Cabrera García 2018: 85).

Tabla 1.- Molinos hidráulicos harineros de la comarca Sierra de Cádiz según las diferentes fuentes de información utilizadas. F1: Catastro de Ensenada. F2: Diccionario de Madoz. F3: Minutas planimétricas. F4: aportaciones de Javier Escalera Reyes. F5: Base de Datos de Patrimonio Inmueble del IAPH. Fuente: elaboración propia

\begin{tabular}{|l|l|l|l|l|l|}
\hline & F1 & F2 & F3 & F4 & F5 \\
\hline No de molinos & 61 & 36 & 81 & 63 & 12 \\
\hline
\end{tabular}


APLICACIÓN Y ANÁLISIS. Establecimiento de cuestiones que intentan ser respondidas mediante planos, dibujos y textos, dibujos.

- 5. Trabajo de campo: Al conjunto previo de saberes centrados en la "materialidad de lo rural" (Guerra de Hoyos 2008: 19) se le incorpora una segunda mirada: la del trabajo de campo, necesario tanto para verificar la ubicación y comprobar el estado de conservación de los molinos, como para interpretar y construir el propio paisaje que, como concepto subjetivo, necesita de la interacción con el territorio, con el lugar. "Our personal sense of place depends upon our own experiences and sensibilities. It is unique to each of us in its content and in the way it relates to general social definitions of places. Thus each of us creates and accumulates places"7 (Meinig 1979: 3).

El trabajo de campo, organizado por riberas, se ha realizado en junio, julio y agosto de 2016. En primer lugar, como trabajo preparatorio previo, ha sido necesario identificar los molinos hidráulicos a nivel documental (Minutas Planimétricas antes mencionadas); en segundo lugar, la traslación a la planimetría actual. Para ello, se abren tres vías. Por un lado, se ha trabajado con la última actualización del Mapa Topográfico Nacional a escala 1:25000 (hoja 1050) disponible en el IGN (en estos mapas se detectan muchas ausencias de molinos) y con los archivos topográficos vectoriales (dwg) disponibles en la Base Cartográfica de Andalucía del IECA. Por otro, y una vez se tenían los molinos con la localización más aproximada posible en versión cad, se ha utilizado GoogleMaps $\odot$ para crear un archivo kmz con el emplazamiento de los molinos [figura 8]. Muchos molinos mantienen su infraestructura distintiva -caos, cubos y en ocasiones embalses- perceptibles desde la visión aérea que proporciona GoogleMaps $\odot$, por lo que su ubicación resulta más rápida al contar con sus coordenadas geográficas exactas. Esto permite estudiar su accesibilidad con el propio GoogleMaps@) (caminos, veredas o carriles más próximos al molino concreto). Pero muchos otros molinos son imperceptibles desde las imágenes aéreas, bien porque sus rasgos definitorios han desaparecido, bien porque se encuentran en ruinas o bien porque la abundante vegetación que los suele
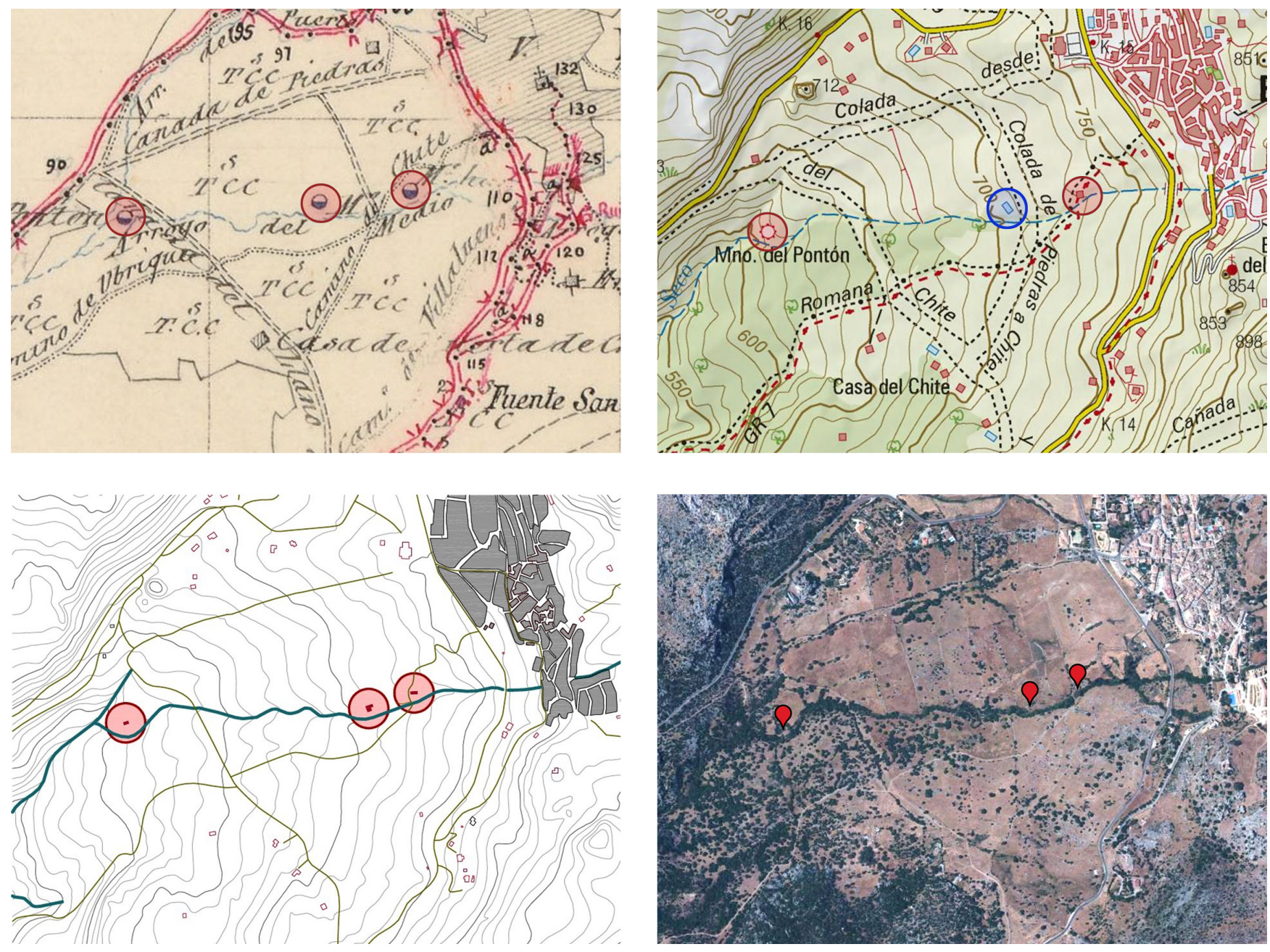

Figura 8.- Mapas sincronizados de la ribera del Arroyo Seco, en Benaocaz. Localización de 3 molinos hidráulicos: "Primero", "Segundo" $y$ "El Pontón". Siguiendo el orden de escritura: Minuta Planimétrica 1873; Mapa Topográfico Nacional escala 1:25000; archivos topográficos vectoriales; kmz de GoogleMaps $\odot$. Fuentes: elaboración propia a partir de los mapas disponibles en el IGN, IECA y GoogleMaps $\odot$ 
acompañar dificulta su visión. El icono de molino harinero en la minuta cartográfica (un círculo azul semicoloreado) se extrapola a un terreno amplísimo en la realidad, añadiendo a esto la posibilidad de que el molino haya desaparecido por completo en la actualidad. Una vez realizado este trabajo preparatorio, se desarrolla el tercer requisito: la expedición. Con el mapa kmz elaborado

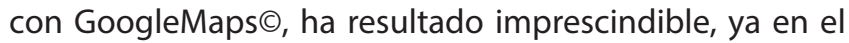
terreno, un dispositivo móvil donde poder visualizarlo. También ha sido importante disponer de GPS, de manera que se fuesen marcando posición y movimientos. Las jornadas estaban programadas para visitar una media de 3 o 4 molinos por día. Igualmente, para ampliar la escala del trabajo y disponer de otro punto de vista, de una mirada más, se ha hecho uso de un dron, lo que ha permitido obtener interesantes perspectivas de los molinos y su entorno [figuras 1 y 3 ].

El trabajo de campo ha permitido contabilizar y localizar un total de 85 molinos hidráulicos en la Sierra de Cádiz. Este paso conlleva la realización de un inventario de los molinos de la zona, integrando la información obtenida a partir del análisis documental y la toma de datos in situ mediante fichas técnicas según modelo diseñado para esta investigación.

- 6. Fichas de molinos: La relación de molinos hidráulicos estudiados individualmente son los que corresponden a los términos municipales que principalmente conforman el Parque Natural Sierra de Grazalema: Zahara de la Sierra, Grazalema y Benaocaz [figura 2]. Las fichas técnicas diseñadas se componen de dos hojas, cada una nombrada con el siguiente código: $X-Y \_1 / 2$ y $X-Y \_2 / 2$, donde $X$ es la inicial del municipio donde se encuentre el molino e $Y$ es el número del molino estudiado (estos se numeran siguiendo el sentido de la corriente del cauce) [figura 9]. Este criterio es el que se ha seguido en la elaboración de nuevas planimetrías. La primera hoja de las fichas corresponde a la localización del molino concreto en la Sierra de Grazalema. La segunda hoja de las fichas consta de los apartados que se enumeran y explican en la primera parte de la figura 9.

- 7. Captar las relaciones y los vínculos: Que establecen los molinos hidráulicos con el territorio, con los caminos, con otras construcciones y con la sociedad. Estudiar la evolución: la evolución histórica, por la datación y por el análisis del contexto en el que han surgido los molinos hidráulicos; la evolución de los paisajes, de las construcciones y de sus usos, de los cultivos y usos del suelo, de las condiciones sociales y culturales...

- 8. Elaboración de nuevas planimetrías: La elaboración de nuevas planimetrías puede ser uno de los métodos más explicativos y esclarecedores para plasmar análisis y estudios del territorio, siempre con base en planos históricos. Se realizan en esta investigación 8 mapas que responden a distintas escalas y tiempos: nivel provincial -Cádiz-, comarcal -Sierra de Cádiz- y subregional -parte del Parque Natural Sierra de Grazalema-, dibujando en cada caso la orografía, hidrografía, red viaria, infraestructuras históricas [figura 10] y actuales para solaparlas y extraer conclusiones, y cultivos históricos, y superpuestos a todos ellos, siempre, la red de molinos hidráulicos.

- 9. Organización de la información: Se hace necesario codificar todo este conocimiento a través de la elaboración de bases de datos.

\section{SÍNTESIS Y EVALUACIÓN. Construcción del paisaje y conclusiones.}

- 10. Miradas: El conocimiento teórico y objetivo previo, tanto de la zona objeto de estudio y su realidad física como de la base conceptual del paisaje deriva, con el fundamental trabajo de campo, en una mirada personal hacia el territorio, una visión del mismo que se traduce en una construcción del paisaje, una creación emocional. Estas miradas se llevan a cabo a través de la expedición, de jornadas de trabajo de campo por las diferentes riberas de la Sierra de Grazalema, y se transmiten a través de fotos y ortofotos realizadas con dron, textos, reflexiones y dibujos [figura 11]. Los dibujos, de elaboración propia, intentar sintetizar los aspectos claves del paisaje; así, la mirada se plasma a través de una representación gráfica que es personal pero pretende ser fidedigna a la vez, reconociendo de esta forma el carácter eminentemente visual del paisaje e introduciendo al observador/lector en el proceso de configuración de la imagen paisajística. Estas miradas se analizan a través de unos elementos y componentes paisajísticos cuya interacción genera un paisaje determinado, propio, con matices diferenciadores para cada ribera. Como afirma González Fraile (2009: 17), "el paisaje no es sino la razón completa de una realidad, de un plegamiento de órdenes y armonías no bien conocidos: en definitiva, el argumento que fundamenta un contexto. El arquitecto debe saber leer el texto o los textos presentados por el paisaje. Desvelar el guión, el de la historia y el del futuro, el del material y lo que evoca".

Resulta imposible establecer una lista única de componentes paisajísticos. Las dimensiones y características propias del territorio, los fundamentos teóricos así como la experiencia de las expediciones han conducido a establecer las siguientes pautas de observación: rasgos físicos (topografía y forma del terreno, vegetación y usos de suelo, horizontes...), percepción (temperatura, viento, sombra, color, luz, intensidad, sonidos...), relaciones (de los molinos con la topografía, con el río, con los caminos y sendas...), distancias (entre molinos, con otras arquitecturas dispersas, con el núcleo de población...), vinculaciones (molinos conexos, inconexos, molinos en simbiosis con la naturaleza por contribuir a los sistemas de regadío...), resiliencia (re-habilitaciones, dilataciones, la ruina conservada o el olvido) y materialidad (construcción, materiales, técnicas...). 


\section{IDENTIFICACIÓN}

REFERENCIA: XXX-Y, donde XXX corresponde a las tres primeras letras de la ribera en la que se localiza el molino, e $Y$ es el número del molino estudiado.

NOMBRE ACTUAL: con base en la información de las últimas fuentes o de los propios informantes.

NOMBRE S. XIX: es el nombre que se recoge en las Minutas Cartográficas de 1873.

RIBERA: en la que se localiza el molino estudiado.

MUNICIPIO: en el que se localiza el molino estudiado.

COORDENADAS: son las que proporciona GoogleMaps®, en grados decimales.

ALTITUD: cota en metros.

ACCESIBILIDAD: comentario sobre la accesibilidad al molino (acceso rodado, a pie, distancias, dificultad, etc.).

\section{CARACTERIZACIÓN}

DESCRIPCIÓN: breve descripción de la estructura del molino y de otros aspectos que sean relevantes.

ESTANQUE: Sí / No CUBOS: número ( 1 o 2$)$

CONSERVACIÓN: Buena / Regular / Mala / - (ha desaparecido)

NUEVOS USOS: si los tiene.

CULTIVOS ACTUALES: con base en el trabajo de campo y en la última actualización del MTN escala 1:25000.

CULTIVOS S. XIX: con base en los cultivos que se recogen en la Minutas Cartográficas de 1873.

OBSERVACIONES: que se consideren oportunas.

\section{REFERENCIAS}

FUENTES: pueden ser tres: Minuta Cartográfica 1873 / J. Escalera Reyes / Base de datos del IAPH.

INFORMANTE: si lo ha habido (propietario, vecino de la zona...)

EMPLAZAMIENTO

Planimetría en la que aparecen los molinos (sombreados en rojo, resaltados con un círculo del mismo color), otras edificaciones, caminos, ríos y curvas topográficas.

VISTA

Imagen del molino y su entorno próximo, la mayoría tomadas con dron y otras con cámara fotográfica.

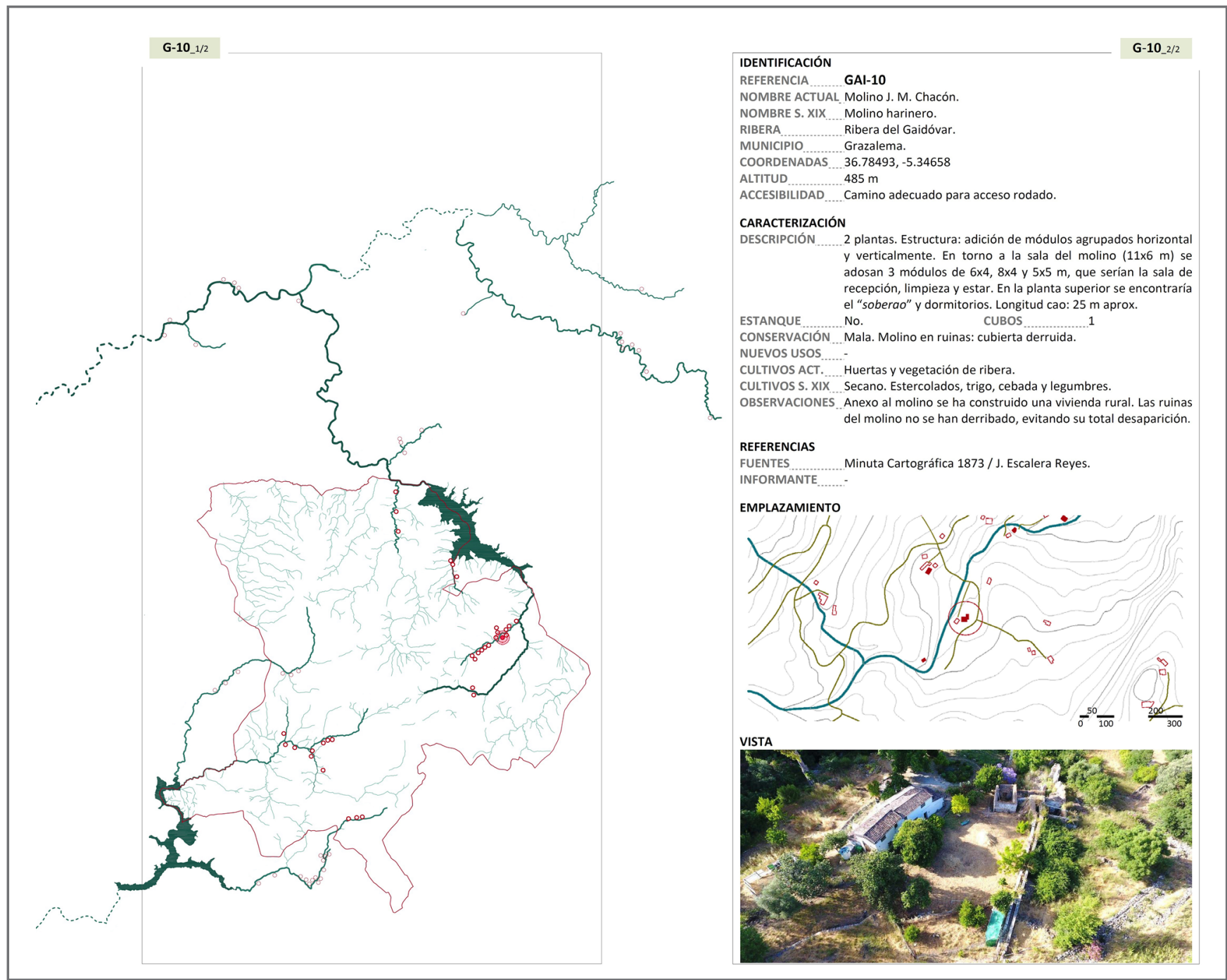

Figura 9.- Ejemplo de Ficha de Molino elaborada. Fuente: elaboración propia 


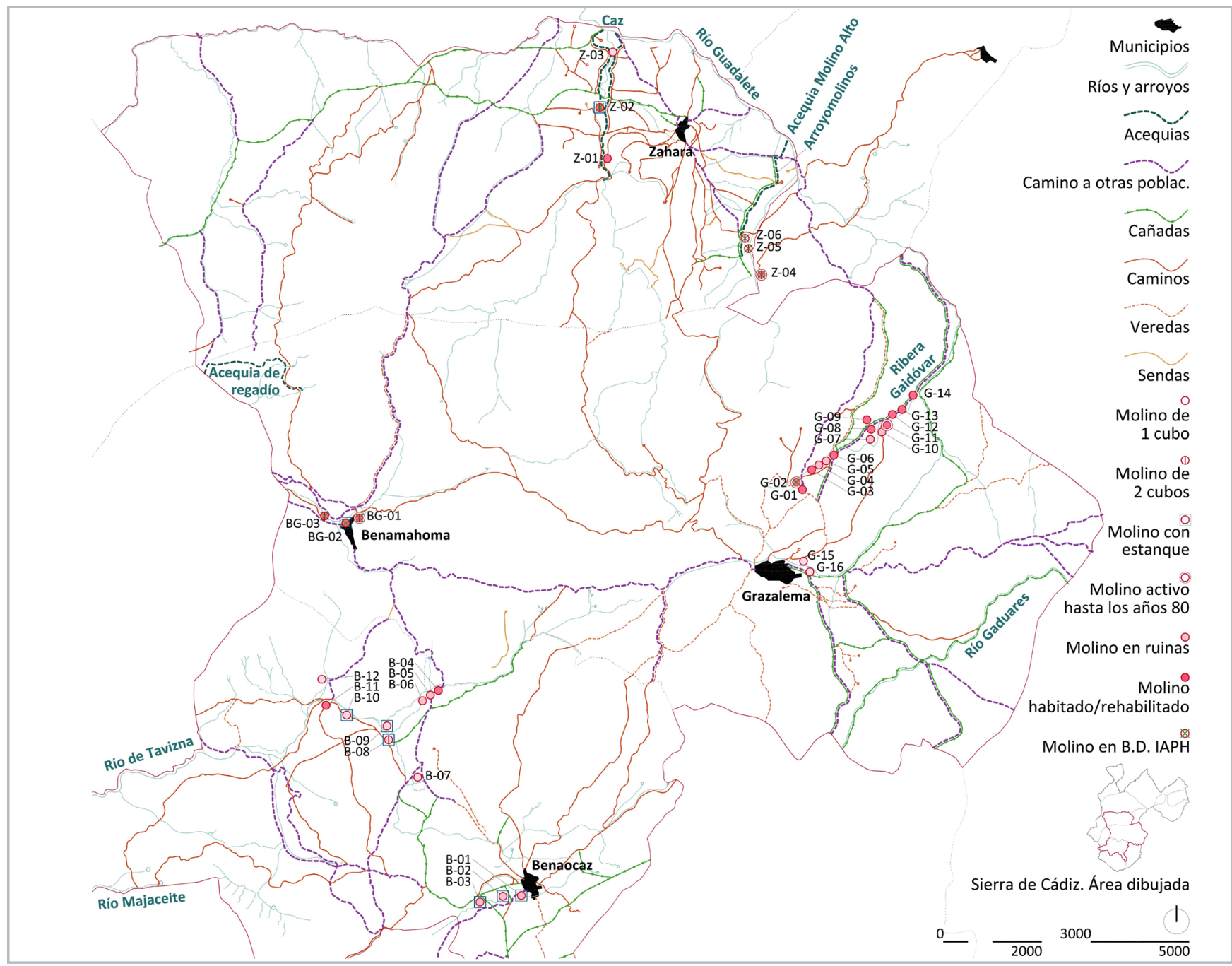

Figura 10.- Mapa de las infraestructuras históricas de los molinos hidráulicos de la Sierra de Grazalema (municipios: Zahara, Grazalema y Benaocaz). Localización de 37 molinos hidráulicos indicando sus características. Fuente: elaboración propia con base en las Minutas Planimétricas de 1873

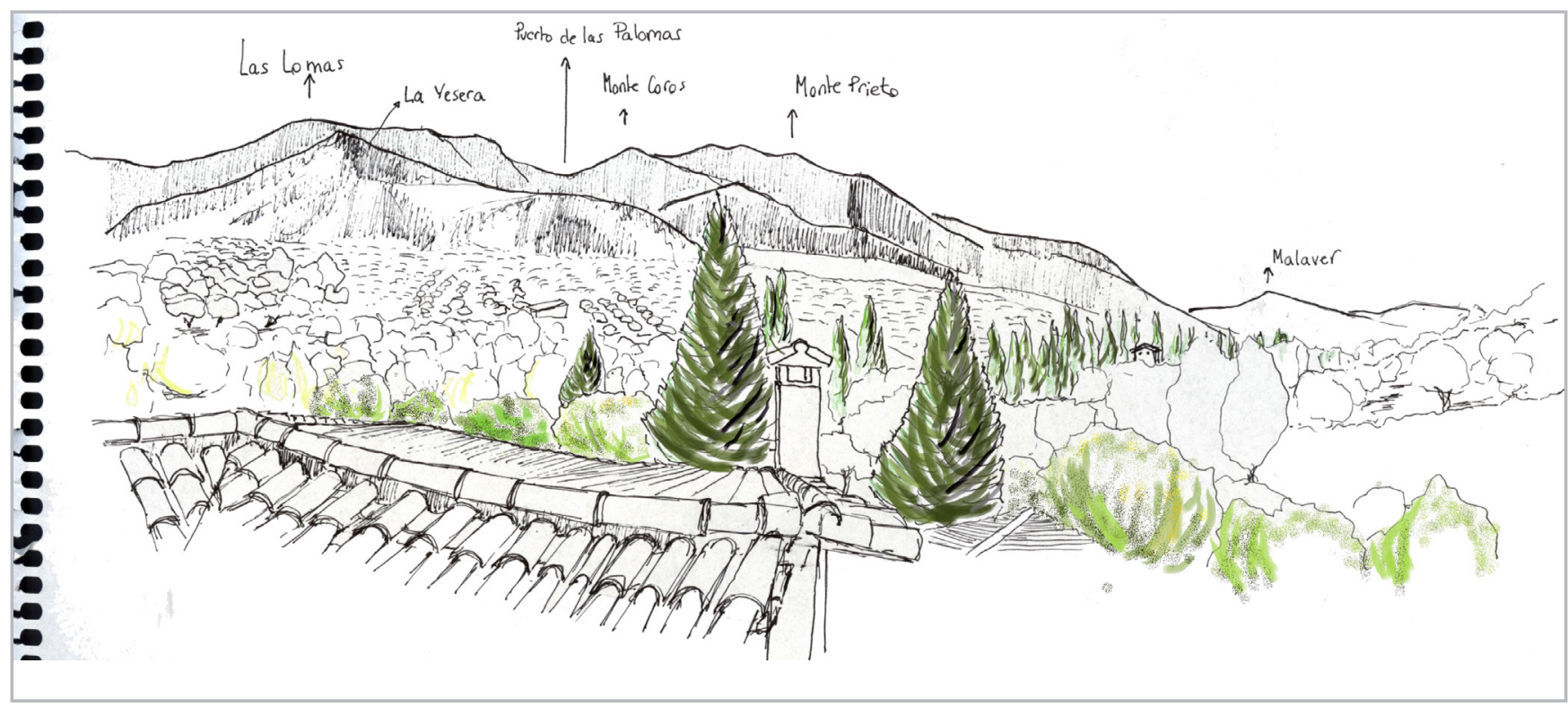

Figura 11.- Dibujo del horizonte norte de la ribera del Gaidóvar norte desde el cao del molino “El Rincón”. Fuente: elaboración propia 


\section{Aportaciones relevantes}

La metodología aplicada trata de poner en valor los molinos hidráulicos de la Sierra de Cádiz e interpretar el territorio a partir de estas arquitecturas. De esta manera, se preservan unos paisajes rurales poco valorados y una memoria colectiva que tienen en estos edificios rurales y productivos su principal espejo. Para estimar, valorar, proteger y aprender de estos paisajes patrimoniales se hace necesario conocer objetivamente el territorio y el objeto $y$, paralelamente, re-conocer cómo se han modelado con el paso de los años. Es esta la finalidad primordial de la investigación que trata de argumentarse a lo largo de todo el trabajo, aunque se pueden destacar aportaciones concretas y determinadas:

- El inventario de los molinos hidráulicos existentes en la Sierra de Cádiz, información inexistente. Para ello, se ha diseñado un modelo de ficha técnica [figura 9] que integra la información obtenida a partir del análisis documental y la toma de datos del trabajo de campo y aportan información sobre su identificación, caracterización, referencias, emplazamiento y vista. Este material facilitaría su inclusión en las bases oficiales del IAPH.

- La datación fotográfica con ortofotos realizadas con dron de los molinos hidráulicos y su entorno, de los paisajes de la Sierra de Cádiz.

- La elaboración de nuevas planimetrías territoriales de la comarca con la ubicación de los molinos hidráulicos: descriptivas y objetivas; subjetivas y de síntesis. Todas ellas plasman análisis y estudios del territorio, expresando estados pasados, presentes, transformaciones y evoluciones, siempre con base en planos históricos y reconocimiento directo del territorio.

\section{Conclusiones}

\section{Sobre el objeto de estudio.}

Los molinos hidráulicos de la Sierra de Cádiz constituyen uno de los conjuntos constructivos más valiosos, sustanciales y didácticos de la arquitectura de la comarca por diversos motivos:

- Por conformar una red de más de 80 molinos extendida por las riberas serranas; son las edificaciones rurales de carácter industrio-artesanal (sin incluir los ranchos o casas de campo) principales y más numerosas de la Sierra de Cádiz, superando a batanes, cortijos, almazaras, cillas, tercias o pósitos.

- Por ser partes constitutivas de un paisaje con valor patrimonial, explicativas y constructoras del territorio en el que se sitúan.
- Por contribuir a justificar la estructura social, cultural y económica de esta región, permitiendo obtener una lectura logística del territorio.

- Por ser origen de vida y cultura, generadores de estructuras viarias, caminos y sendas.

- Por ser soporte del patrimonio inmaterial, parte fundamental del patrimonio cultural y ser expresión de la sociedad serrana al englobar los saberes de la que fue una de las principales actividades de la comarca, la molienda.

- Por poseer todos ellos características constructivas, formales, espaciales, funcionales y simbólicas comunes que permiten establecer una clasificación: la totalidad de los molinos que aparecen en la Sierra de Cádiz son de rueda horizontal o rodezno, poseen uno o dos cubos y pueden o no tener estanque.

- Porque, a pesar de tener características comunes, existen matices diferenciadores entre los molinos de diferentes riberas, lo que enriquece y estimula su estudio global comarcal.

- Por ser prototipos arquitectónicos, es decir, arquitecturas que enseñan valores constructivos y estrategias de diseño "que ayudan a entender la lógica de la arquitectura por encima de los avances y descubrimientos producidos por ciencias, ingenierías e industrias" (Ramos-Carranza 2013: 15): por la precisión de los medios empleados, por resolverse de manera eficaz, por ser arquitecturas sustentadas en la topografía y las infraestructuras geográficas naturales, por integrarse en el contexto en perfecta armonía con el medio, emanando del propio territorio...

- Por ser arquitecturas sostenibles, que emplean recursos del entorno no contaminantes y energías renovables, y contienen "inherent, unwritten information about how to optimize the energy performance of buildings at low cost using local materials"8 (Zhai y Previtali 2010: 357). En el caso de los molinos hidráulicos, el agua es la fuerza motriz. Esta, canalizada por las conducciones que aprovechan y soslayan la topografía, se usa para regar cultivos y huertas circundantes, y se devuelve al cauce una vez es activado el mecanismo del molino, creándose un circuito pseudonatural perfectamente integrado en el entorno.

Su ajuste a la necesidad y a las condiciones del medio y la no especulación ni sobreproducción revelan el carácter de un compromiso, cualidad que debe ser eidética de la arquitectura y de otras muchas disciplinas y que se puede aprender analizando estos molinos. Así lo detecta Paul Oliver (2006: 14):"It is not only in the use of energy that we can learn about the employment of natural resources (...). Many societies have achieved an ecological balance which 
maintains, in a steady state, the relationship between the availability of a resource and their consumption of it; I need hardly emphasize that this is a lesson that we certainly need to learn"9.

Arquitecturas aletargadas pero de las que se pueden adquirir profundos conocimientos; arquitecturas obsoletas que pueden tener un papel clave en el presente y futuro de la comarca gracias a su estudio, lectura, valorización, protección y recuperación. Los molinos podrían resurgir con nuevos usos siempre y cuando no se conciban como elementos asilados, sino mediante "propuestas integrales de paisajes-itinerarios" (Benito del Pozo et al. 2016: 153) que enlacen de manera coherente esta red (pre)industrial con su pasado funcional y su territorio, y consideren su legado intangible; "its sensitivity and compose with creativity to enhance the hidden cultural references"10 (Versaci et al. 2016: 26).

\section{Sobre el tema de la investigación}

Reflexionar sobre la construcción del paisaje de la Sierra de Cádiz requiere un dominio científico e intelectual de las partes que lo componen $y$, unido a ello, es esencial la sensibilidad del "constructor" de paisajes, pues entendemos el paisaje como una manera de ver, "una extensión de terreno bastante amplia que puede captarse con la mirada y que es considerada desde un cierto punto de vista, el de un observador situado" (Cauquelin 1990: 104). Un observador que percibe el paisaje como un palimpsesto conformado por capas culturales superpuestas que lo transforman en metáfora visual del territorio. Esta doble perspectiva, la científica y la subjetiva e íntima se complementan y concilian al elegir un enfoque concreto: los molinos hidráulicos. Estas miradas se sistematizan de la siguiente manera: al llevarse a cabo a través de la expedición; al dirigir la visión siempre hacia los molinos y su entorno o desde los molinos hacia el entorno -hacia el interior, hacia el exterior-, en este caso, siempre desde los mismos elementos, los caos y cubos de los molinos (por su fisonomía y altura permiten una fructífera imagen del entorno); al materializarse a través de dibujos, fotos, ortofotos y reflexiones; los textos intentar atender a las variables visibles y no visibles, a sus interacciones y a los elementos que componen el territorio -rasgos físicos, percepción, relaciones, distancias, vinculaciones, resiliencia y materialidad-, que cuando son mirados y pensados, construyen el paisaje.

\section{Reflexión}

Los mapas, dibujos, fotos y textos de este Trabajo, además de intentos de construcción de un paisaje concreto, son ventanas; es decir, encuadres, perspectivas, planos enmarcados de un modo electivo o discrecional que invitan a mirar, incitan a ver. Y podrían ser también una preparación, una introducción para observar el territorio elegido porque, como dice Thoreau (2002: 68), "en el paisaje hay exactamente la belleza que uno está preparado para ver, ni un gramo más".

Uno de los aforismos patrimoniales más extendidos, "conocer para valorar, valorar para proteger", podría resumir los esfuerzos de esta investigación. Conocer la Sierra de Cádiz y sus molinos hidráulicos, tipología edificatoria apenas tratada pero que cuenta con suficiente entidad, valores patrimoniales y presencia en el territorio como para ser considerada parte fundamental de su configuración y de sus paisajes, provoca, inevitable y afortunadamente, descubrir los valores asociados que sus paisajes irradian. Esto da lugar a protegerlos; pero no ha sido el objeto de este Trabajo plantear una protección de grado legal o institucional, sino personal, de cuidado, valorización y respeto al medio, a su naturaleza, que siempre persistirá, a sus construcciones históricas, a estos molinos harineros que, per se, transmiten historias del pasado y del presente que invitan a reflexionar sobre el futuro. El mundo global en el que vivimos nos ha hecho conscientes de una certeza determinante: la acción del hombre es capaz de desequilibrar el ritmo natural del planeta y desde esta perspectiva, la arquitectura vernácula y sus paisajes parecen encontrarse "in the almost inevitable process of being altered or replaced by unsustainable modern building practices associated with industrialisation, modernity and the global market"11 (Vellinga 2013: 579). Ante este panorama, parece importante una toma de conciencia: construir una mirada y una interpretación propias de nuestro tiempo, para, de esta manera, poder comprender nuestro momento y, a continuación, ser capaces de proponer acciones futuras sostenibles, coherentes e integradoras en la clave temporal que nos corresponde.

\section{Notas}

[1] Este artículo resume la estructura y contenidos principales del Trabajo Fin de Máster del Máster en Arquitectura y Patrimonio Histórico de la Universidad de Sevilla de la autora, Gloria Rivero Lamela, defendido el 2 de diciembre de 2016. Tutores: Dra. María Teresa Pérez Cano y Dr. Francisco Montero Fernández. / This paper summarizes the structure and main contents of the Master Thesis of the Master's Degree in Architecture and Historic Heritage from the University of Seville by the author, Gloria Rivero Lamela, defended on December 2nd, 2016. Tutors: Dra. María Teresa Pérez Cano and Dr. Francisco Montero Fernández.. Este trabajo consiguió el segundo premio en la convocatoria Joven Investigador GEIIC 2018. https://www.congreso2018.ge-iic.com/ es/convocatoria-premio-joven-investigador-en-conservaciony-restauracion-2018/relacion-de-candidaturas-finalistasa-optar-al-premio-joven-investigador-en-conservacion-yrestauracion-2018/

[2] La Sierra de Cádiz es una de las cinco comarcas agrarias que establece el Ministerio de Agricultura, Pesca y Alimentación para la provincia de Cádiz; según la última publicación de 2012, la comarca cuenta con una superficie de 105.435 ha $(14,2 \%$ de la 
superficie provincial) y administrativamente está compuesta por 14 municipios: Alcalá del Valle, Algodonales, Benaocaz, El Bosque, El Gastor, Grazalema, Olvera, Prado del Rey, Puerto Serrano, Setenil de las Bodegas, Torre Alháquime, Ubrique, Villaluenga del Rosario y Zahara de la Sierra. Esta comarca comprende gran parte del Parque Natural Sierra de Grazalema (un 72\%), declarado Reserva de la Biosfera en enero de 1977 y Parque Natural por la Junta de Andalucía en diciembre de 1984.

[3] Traducción de la autora: "cada uno definido por los procesos de modificación y estratificación que se produjeron a lo largo de los siglos, constituyendo testimonios de culturas y eventos pasados".

[4] De los 85 molinos harineros existentes en la Sierra de Cádiz, ninguno de ellos está en el Catálogo General del Patrimonio Histórico Andaluz (CGPHA), y solo 12 están en la Base de Datos del Patrimonio Inmueble de Andalucía (BDI) del IAPH mediante fichas sucintas.

[5] Traducción de la autora: “Un paisaje no es una característica natural del medio ambiente, sino un espacio sintético, un sistema de espacios hecho por el hombre superpuestos a la superficie de la tierra, que funciona y evoluciona no de acuerdo con las leyes naturales, sino para servir a una comunidad (...). Es una cosa que todas las generaciones y todos los puntos de vista han acordado".

[6] El Comité de altos funcionarios de la Conferencia europea de ministros responsables de la ordenación del territorio (CEMAT) adoptó la Guía Europea de observación del patrimonio rural-CEMAT en 2003, con ocasión de la 13a sesión de la CEMAT, celebrada en Budapest (CEMAT CHF 80 (2003) 19).

[7] Traducción de la autora: "Nuestro sentido personal del lugar depende de nuestras propias experiencias y sensibilidades. Es único para cada uno de nosotros en su contenido y en la forma en que se relaciona con las definiciones generales sociales de los lugares. Por lo tanto, cada uno de nosotros crea y acumula lugares".

[8] Traducción de la autora: "información inherente y no escrita sobre cómo optimizar el rendimiento energético de los edificios a bajo costo utilizando materiales locales".

[9] Traducción de la autora: “No es solo en el uso de la energía lo que podemos aprender sobre el empleo de los recursos naturales (...). Muchas sociedades han logrado un equilibrio ecológico que mantiene, en un estado de estabilidad, la relación entre la disponibilidad de un recurso y el consumo del mismo; no hace falta enfatizar que esta es una lección que sin duda necesitamos aprender".

[10] Traducción de la autora: "su sensibilidad y compongan con creatividad para realzar las referencias culturales ocultas".

[11] Traducción de la autora: "en el proceso casi inevitable de ser alterada o reemplazada por prácticas de construcción modernas insostenibles asociadas con la industrialización, la modernidad y el mercado global".

\section{Bibliografía}

AA. VV. (2006). Guía Europea de observación del patrimonio rural CEMAT. [S. I.]: Centro de Publicaciones. Secretaría General Técnica del Ministerio de Medio Ambiente.

BENITO DEL POZO, P., CALDERÓN CALDERÓN, B., PASCUAL RUIZVALDEPEÑAS, H. (2016). "La gestión territorial del patrimonio industrial en Castilla y León (España): fábricas y paisajes", Investigaciones Geográficas, Boletín del Instituto de Geografía, UNAM, 90: 136-154. DOI: http://dx.doi.org/10.14350/rig.52802

CABRERA GARCÍA, V. M. (2018). "Alternativas para revitalizar los molinos de viento tradicionales de las Islas Canarias", Geconservación, 13: 80-92.

CAUQUELIN, A. (1990). "Le paysage et son dessein”. En: L'humanisme en géographie, Bailly, A. y Scariati, R. París: Anthropos, 101-110.

CENTOFANTI, M., BRUSAPORCI, S., LUCCHESE, V. (2016). “Historical Watermills. Architectural, Mechanical and Hydraulic Heritage". En: Essays on the History of Mechanical Engineering. History of Mechanism and Machine Science, vol 31. Sorge F., Genchi G. (eds). Springer, 81-97.

ESCALERA REYES, J. (1980). "Los molinos de agua en la Sierra de Cádiz (Primera campaña)", Etnografía española, 1: 267-374.

ESCALERA REYES, J. (1984). "Los molinos de agua en la Sierra de Cádiz (Segunda campaña)", Etnografía española, 4: 7-50.

GONZÁLEZ FRAILE, E. (2009). "Proyectar arquitectura es reconocer el lugar". En: Arquitectura y construcción. El paisaje como argumento, Ramos Carranza, A. y Añón Abajas, R. M. (dirs.). Sevilla: Universidad Internacional de Andalucía, 17-28.

GREGOTTI, V. (1972). El territorio de la Arquitectura. Barcelona: Escuela Técnica Superior de Arquitectura.

GUERRA DE HOYOS, C. (2008). La contemporaneidad de la arquitectura rural: adaptación, resistencia o dilatación. Sevilla: Universidad de Sevilla, C.O.P.T.

JACKSON, J. B. (1984). Discovering the Vernacular Landscape. New Haven: Yale University Press.

MEINIG, D. W. (1979). The interpretation of ordinary landscapes: geographical essays. New York, NY: Oxford University Press.

OLIVA SERRANO, J. (1997). “Estructuración y reestructuración de espacios y sociedades rurales. Nuevas reflexiones sobre unos procesos no esperados", Zainak. Cuadernos de AntropologíaEtnografía, 14: 321-337.

OLIVER, P. (2006). Built to Meet Needs. Cultural Issues in Vernacular Architecture. Oxford: Elsevier.

OLMEDO GRANADOS, F. (2002). "La arquitectura agraria en Andalucía". En: Cortijos, haciendas y lagares en Andalucía: 
Arquitectura de las grandes explotaciones agrarias en Andalucía. Provincia de Cádiz, Olmedo Granados, F. (coord.).Sevilla: Junta de Andalucía, C.O.P.T., 13-19.

RAMOS-CARRANZA, A. (2013). "Construyendo formas del pensamiento", Proyecto, progreso arquitectura. Forma y construcción en arquitectura, 8: 12-15. DOI: http://dx.doi. org/10.12795/ppa.2013.i8.13

RAMOS-CARRANZA, A. y RIVERO-LAMELA, G. (2018). "El valor de las arquitecturas menores: Los molinos hidráulicos del Parque Natural Sierra de Grazalema en la Sierra de Cádiz", Estoa, Revista de la Facultad de Arquitectura y Urbanismo de la Universidad de Cuenca, 7(13): 85-99. DOI: http://dx.doi.org/10.18537/est.v007. $\underline{\mathrm{n} 013 . \mathrm{a} 07}$

SUÁREZ JAPÓN, J. M. (1982). El hábitat rural en la Sierra de Cádiz: un ensayo de geografía del poblamiento. Cádiz: Diputación de Cádiz.

THOREAU, H. (2002, $18621^{\text {a }}$ ed.). Colores de otoño. Barcelona: Torre de viento.

VELLINGA, M. (2013). "The noble vernacular", The Journal of Architecture, 18(4): 570-590. DOI: https://doi.org/10.1080/13602 365.2013.819813

VERSACI, A., CARDACl, A., RENATO FAUZìA, L. (2016). "Recovery and Conservation of Old Water Mills in Central Sicily". En: Conservation of Architectural Heritage (CAH), Procedia - Social and Behavioral Sciences, vol. 225, 15-26

ZHAI, Z., y PREVITALI, J. (2010). “Ancient vernacular architecture: Characteristics categorization and energy performance evaluation", Energy \& Buildings, 42(3): 357-365. DOI: http://dx.doi. org/10.1016/j.enbuild.2009.10.002

\section{Autora}

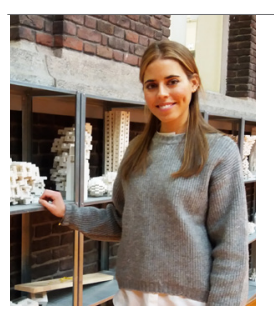

\section{Gloria Rivero-Lamela}

grivero@us.es

Escuela Técnica Superior de Arquitectura. Universidad de Sevilla

Arquitecta (2014) por la Universidad de Sevilla. Premio Extraordinario de Fin de Estudios en el título universitario oficial de Arquitecta otorgado por la Universidad de Sevilla (2015). Premio de La Real Maestranza de Caballería de Sevilla y del Excmo. Ayuntamiento de Sevilla al mejor expediente académico de su promoción. Máster en Arquitectura y Patrimonio Histórico (2016). Actualmente, contratada predoctoral PIF de la Universidad de Sevilla y doctoranda en el Departamento de Proyectos Arquitectónicos de la Escuela Técnica Superior de Arquitectura de Sevilla, donde combina investigación y docencia. Ha realizado una estancia de investigación en la Faculty of Architecture and the Built Environment de la Delft University of Technology (TU-Delft).
Es miembro del Grupo de Investigación HUM 632: "Proyecto, progreso, arquitectura". Su investigación y tesis en curso abordan temas relacionados con el territorio, el paisaje y las arquitecturas rurales.

Perfil SISIUS: https://investigacion.us.es/sisius/sis showpub. php?idpers $=20068$

Perfil ORCID: https://orcid.org/0000-0002-8683-0704

Artículo enviado el 11/10/2018 Artículo aceptado el 14/12/2018 